\title{
KARAKTERISTIK BIOFISISK DAN SOSIAL EKONOMI YANG MEMPENGARUHI PRODUKTIVITAS LAHAN SAWAH PADA KAWASAN DAERAH ALIRAN SUNGAI PADANG GUCI KABUPATEN KAUR
}

\author{
Dian Sari $^{1}$, M. Faiz Barchia ${ }^{2}$, Bandi Hermawan ${ }^{2}$ \\ 1) Program Studi Pasca Sarjana Pengelolaan Sumberdaya Alam dan Lingkungan, \\ Fakultas Pertanian Universitas Bengkulu. \\ 2) Jurusan Agroteknologi, Fakultas Pertanian, Universitas Bengkulu
}

\begin{abstract}
ABSTRAK
Pertumbuhan penduduk yang tidak diimbangi dengan pertumbuhan produksi bahan pangan akan menimbulkan permasalahan pangan. Salah satu upaya yang harus dilakukan untuk mencegah timbulnya masalah ketersediaan pangan adalah pemaksimalan penggunaan lahan pertanian, dengan meningkatkan irigasi pada daerah aliran sungai dan diversifikasi pangan sehingga indeks pertanaman pangan akan meningkat. Penelitian ini dilakukan di empat wilayah kecamatan, yaitu Tanjung Kemuning, Kaur Utara, Padang Guci Hulu, Padang Guci Hilir, pada Daerah Aliran Sungai Padang Guci, Kabupaten Kaur. Tujuan dari penelitian ini adalah untuk mendapatkan data tentang produktivitas sumberdaya lahan sawah pada Daerah Aliran Sungai Padang Guci Kabupaten Kaur dan data tentang tingkat perlakuan usaha tani padi sawah pada DAS tersebut. Hasil penelitian menunjukkan bahwa masyarakat di daerah Aliran Sungai Padang Guci sangat tergantung pada lahan sawah, yang ditunjukan dengan jumlah penduduk yang mayoritas bekerja sebagai petani. Produksi padi sawah pada Daerah Aliran Sungai Padang Guci belum optimal, sebagaimana terlihat dari hasil rata-rata 4,21 ton/ha yang lebih rendah dari potensi hasil yang berkisar 5 ton/ha $-6,59$ ton/ha, Karakteristik biofisik yang mempengaruhi produksi padi adalah varietas padi, irigasi dan pemupukan, sedangkan karakteristik sosial ekonomi yang mempengaruhi produksi padi adalah umur petani dan tenaga kerja.
\end{abstract}

Kata Kunci: Karakteristik, Biofisik, sosial ekonomi, produktivitas lahan sawah.

\section{PENDAHULUAN}

Kebutuhan bahan pangan terutama beras akan terus meningkat sejalan dengan pertambahan jumlah penduduk dan peningkatan konsumsi per kapita akibat peningkatan pendapatan. Namun dilain pihak upaya peningkatan produksi beras saat ini terganjal oleh berbagai kendala, seperti konversi lahan sawah subur yang masih terus berjalan, penyimpangan iklim (anomaly iklim), gejala kelelahan teknologi (technology fatique), penurunan kualitas sumberdaya lahan (soil sickness) yang berdampak terhadap penurunan dan atau pelandaian produktivitas (Promono, dkk. 2005).

Salah satu kunci keberhasilan swasembada adalah penyediaan input teknologi modern. Penggunaan teknologi modern yang dikenal dengan "Revolusi Hijau" dapat memecahkan masalah kekurangan produksi pangan. Akan tetapi revolusi hijau itu sendiri mendapatkan kritik dalam hal kerusakan lingkungan, terabaikannya teknologi lokal dan kelembagaan lokal. Selain itu revolusi hijau sendiri menimbulkan masalah 
keitdakmerataan dan kemiskinan. Sementara itu kebutuhan beras semakin meningkat, yang tercermin dari masih besarnya impor beras pada tahun 20022004. Kondisi ini terjadi akibat pertumbuhan produksi beras dalam negeri relatif rendah dibandingkan dengan peningkatan jumlah penduduk (Menurut Widodo dalam Vandalisna (2003).

Optimasi produktivitas padi di lahan sawah merupakan salah satu peluang peningkatan produksi gabah nasional. Hal ini sangat dimungkinkan bila dikaitkan dengan hasil padi pada agroekosistem ini masih beragam antar lokasi dan belum optimal. Rata-rata produksi padi adalah 4,7 t/ha, sedangkan potensinya dapat mencapai $6-7$ t/ha. Belum optimalnya produktivitas padi di lahan sawah, antara lain disebabkan oleh; a) rendahnya efisiensi pemupukan; b) belum efektifnya pengendalian hama penyakit; c) penggunaan benih kurang bermutu dan varietas yang dipilih kurang adaptif; d) kahat hara $\mathrm{K}$ dan unsur mikro; e) sifat fisik tanah tidak optimal; f) pengendalian gulma kurang optimal (Makarim $d k k$., 2000).

Pemanfaatan sumberdaya alam secara optimal dan rasional bertujuan untuk meningkatkan kesejahteraan masyarakat. Pemanfaatan sumberdaya alam secara bijaksana sesuai dengan kaidah kelestarian tidak saja akan meningkatkan kesejahteraan masyarakat tetapi juga akan mendapatkan manfaat berkesinambungan. Oleh karena itu pemanfaatan sumberdaya alam yang bijaksana merupakan bagian dari upaya pengelolaan daerah aliran sungai (Sunaryo, dkk. 2002). Penelitian ini bertujuan untuk mendapatkan data tentang produktivitas sumberdaya lahan sawah pada Daerah Aliran Sungai Padang Guci Kabupaten Kaur dan data tentang tingkat perlakuan usaha tani padi sawah pada DAS tersebut.

\section{METODA PENELITIAN}

\section{Lokasi dan waktu}

Penelitian dilakukan di empat wilayah kecamatan (Tanjung Kemuning, Kaur Utara, Padang Guci Hulu, Padang Guci Hilir) pada Daerah Aliran Sungai Padang Guci Kabupaten Kaur. Dipilihnya Wilayah ini sebagai lokasi penelitian karena daerah ini merupakan setral produksi padi untuk kabupaten Kaur. Penelitian ini dilakukan dari bulan Februari sampai bulan Maret 2012.

\section{Pengambilan data}

Populasi dalam penelitian dipilih secara purposive, yaitu masyarakat desa yang menjadi sentra padi sawah di Daerah Aliran Sungai Padang Guci. Penetuan sampel pada penelitian ini menggunakan metode yang dikembangkan oleh Slovin (Kusmayadi, 2000 dalam Yuliansyah, 2008).

$$
n=\frac{N}{N \mathbb{Q}^{2}+1}
$$

$\mathrm{n}=$ Jumlah sampel; $\mathrm{N}=$ Jumlah populasi (dalam hal ini dimaksud adalah jumlah KK yang memiliki lahan sawah di daerah aliran sungai), dan $\mathrm{d}=$ Derajad Kepercayaan $90 \%$ dengan tingkat kesalahan 0,2 (10\%), sehingga

$$
n=\frac{8133}{8133\left(10^{2}+1\right.}=98,78
$$

(Jadi Responden dibulatkan menjadi 99 Responden) 
Pengamatan langsung dilapangan dilakukan untuk memperoleh data mengenai lenis jenis padi yang ditanam, tumbuhan yang ditanam sebagai tanaman selang oleh masyarakat, serta menggunakan literature sebagai perbandingan cara pengoptimalan pemanfaatan lahan sawah. Wawancara yang dilakukan berpedoman dengan kuisioner.

Data sosial ekonomi dan kelembagaan diperlukan untuk memberikan gambaran rona lingkungan sosial, ekonomi, dan budaya masyarakat di wilayah DAS Padang Guci. Data sosial ekonomi diperoleh melalui wawancara terstruktur . Data yang diperlukan meliputi demografi penduduk, sosial masyarakat(tingkat pendidikan), ekonomi masyarakat (mata pencaharian, tingkat pendapatan), dan budaya masyarakat (adat istiadat, kebiasaan, dan lain-lain).

Data karakteristik Biofisik dan sosial ekonomi diperoleh dengan dua cara yaitu : 1). melakukan pengukuran-pengukuran di lapangan dan perhitungan terhadap informasi yang terdapat dalam peta, dan 2) melakukan tabulasi dari data sekunder, khususnya data sosial ekonomi.

\section{Analisis data}

Data-data biofisik disajikan dalam bentuk tabulasi dan gafik. Data tabulasi, dan grafik kemudian dianalisis secara deskriptif kualitatif/kuntitatif berdasarkan kategori/standar yang terdapat pada penelusuran pustaka acuan.

\section{HASIL DAN PEMBAHASAN}

\section{Karakteristik Sosial Ekonomi \\ Responden}

Umur petani responden memiliki kisaran antara 21 Tahun - 60 Tahun dengan rata-rata 39,44 tahun (Tabel 1). Usia 31 - 40 tahun sebanyak 34 responden, dan umur 51-60 tahun yaitu 18 orang responden.

Tabel 1. Distribusi Usia Petani Responden

\begin{tabular}{llll}
\hline No & Usia (Thn) & $\begin{array}{l}\text { Jumlah } \\
\text { (orang) }\end{array}$ & $\begin{array}{l}\text { Persentase } \\
(\%)\end{array}$ \\
\hline 1 & $21-30$ & 19 & 19,20 \\
2 & $31-40$ & 34 & 34,34 \\
3 & $41-50$ & 28 & 28,28 \\
4 & $51-60$ & 18 & 18,18 \\
\hline \multicolumn{4}{l}{ Jumlah } \\
\multicolumn{4}{c}{ Rata Rata 39,44} \\
\multicolumn{5}{l}{ Sumber : Data Primer diolah 2012 }
\end{tabular}

Faktor usia sangat mempengaruhi kinerja petani dalam berusaha tani, dimana nilai produksi meningkat seiring dengan peningkatan usia responden. Persamaan linier dari hubungan antara usia dan produksi yaitu $\mathrm{y}=3.342+0.021 \mathrm{x}, \mathrm{r}=$ 0.532 , dari persamaan ini terlihat bahwa ada pengaruh antara peningkatan umur dan peningkatan produksi padi.

Jumlah tenaga kerja tertinggi adalah 4 orang dengan responden 53 orang dengan persentase $53,53 \%$ sedangkan terendah menggunakan tenaga kerja sebanyak 2 orang dengan jumlah responden 17 orang, dengan persentase $17,17 \%$ (Tabel 2).

Tabel 2. Distribusi Petani Berdasarkan Tenaga Kerja

\begin{tabular}{llll}
\hline No & $\begin{array}{l}\text { Jumlah Tenaga } \\
\text { kerja (Orang) }\end{array}$ & $\begin{array}{l}\text { Jumlah } \\
\text { (orang) }\end{array}$ & $\begin{array}{l}\text { Persentase } \\
(\%)\end{array}$ \\
\hline 1 & 2 & 17 & 17,17 \\
2 & 3 & 29 & 29,29 \\
3 & 4 & 53 & 53,53 \\
\hline Jumlah & 99 & 100,00 \\
\hline
\end{tabular}

Sumber: Data Primer diolah 2012

Hubungan antara tenaga kerja dan produksi mengikuti persamaan garis linier $\mathrm{y}=0.095 \mathrm{x}+3.888, \mathrm{r}=0.999$

Varietas padi Invari merupakan varietas yang dominan ditanam oleh para responden dengan 49 orang responden atau $49,49 \%$, karena varietas invari pada 
saat itu merupakan varietas percontohan dari Dinas Pertanian Kabupaten Kaur. Nilai terendah responden memilih varietas IR 64 yaitu 11 orang atau 11,11\%.

Menurut Balai Besar Penelitian Tanaman Padi, 2008 bahwa perbandingan rata-rata produksi antara varietas Inpari : IR 64 : Ciherang adalah 6,59 t/ha : 5,0 t/ha: 6,0 t/ha.

Produksi rata-rata untuk irigasi $1 / 2$ teknis adalah 5,1 ton/ha dengan Standar Deviasi adalah 0,70 dan 3,53 ton/ha untuk irigasi sederhana dengan standar deviasi 0,68.

Jenis pupuk yang digunakan adalah pupuk Urea, NPK, KCl, SP36 dan Ponska dimana rata-rata pengunaan dosisnya yaitu Urea $150 \mathrm{Kg} / \mathrm{ha}, \mathrm{SP} 36$ dosisnya $100 \mathrm{Kg}$ /ha, pupuk $\mathrm{KCl} 81,25 \mathrm{Kg} / \mathrm{ha}$ dan pupuk Ponska $175 \mathrm{Kg} / \mathrm{ha}$. Responde menggunakan dosis pupuk urea $100 \mathrm{~kg} / \mathrm{ha}$, SP 36100 $\mathrm{kg} / \mathrm{ha}, \mathrm{KCl} 75 \mathrm{~kg} / \mathrm{ha}$ dan ponska $150 \mathrm{~kg} / \mathrm{ha}$ dengan jumlah responden sebanyak 21 orang atau 21,21\%, (Tabel 4).

Produksi tertinggi pada dosis pupuk ke 2 yaitu urea $150 \mathrm{~kg} / \mathrm{ha}$, SP $36100 \mathrm{~kg} / \mathrm{ha}$, $\mathrm{KCl} 75 \mathrm{~kg} / \mathrm{ha}$ dan ponska $150 \mathrm{Kg} / \mathrm{ha}$. Produksi terendah pada penggunaan pupuk dengan dosis urea $150 \mathrm{~kg} / \mathrm{ha}$, SP 36100 $\mathrm{kg} / \mathrm{ha}, \mathrm{KCl} 100 \mathrm{~kg} / \mathrm{ha}$ dan ponska 200 $\mathrm{Kg} / \mathrm{ha}$.

Pemupukan mempengaruhi produksi padi, sebagaimana terlihat dari beragamnya tingkat pemupukan oleh petani, sehingga hasil produksi yang diharapkan masih belum optimal. Terdapat kecenderungan petani lahan sawah irigasi di sentra prosukdi beras untuk selalu menambah takaran pupuk, terutama Nitrogen guna mengatasi permasalahan pelandaian produksi, Pemupukan urea, apabila mengikuti aturan penggunaanya yaitu 265 $\mathrm{Kg} / \mathrm{ha}$, yang dikombinasikan dengan penerapan teknologi yang lain akan meningkatkan efisiensi pemupukan urea

\section{Tabel 3. Distribusi Petani Berdasarkan Varietas Benih Padi}

\begin{tabular}{|c|c|c|c|}
\hline No & Nama Varietas & Jumlah (orang) & Persentase $(\%)$ \\
\hline 1 & Cigelis & 17 & $17,17 \%$ \\
\hline 2 & Invari & 49 & $49,49 \%$ \\
\hline 3 & IR 64 & 11 & $11,11 \%$ \\
\hline 4 & Ciherang & 22 & $22,22 \%$ \\
\hline & Jumlah & 99 & 100,00 \\
\hline
\end{tabular}

Sumber : Data Primer diolah 2012

Tabel 4. Distribusi Petani Berdasarkan Jenis pemupukan

\begin{tabular}{|c|c|c|c|c|c|c|c|c|}
\hline \multirow[t]{2}{*}{ No } & \multicolumn{4}{|c|}{ Jenis Pupuk } & \multirow[t]{2}{*}{ Total } & \multirow{2}{*}{$\begin{array}{l}\text { Jumlah } \\
\text { (Orang) }\end{array}$} & \multirow{2}{*}{$\begin{array}{l}\text { Persentase } \\
(\%)\end{array}$} & \multirow{2}{*}{$\begin{array}{l}\text { Produksi rata-rata } \\
\text { (ton/ha) }\end{array}$} \\
\hline & Urea & SP36 & $\mathrm{KCl}$ & Ponska & & & & \\
\hline 1. & 100 & 100 & 75 & 150 & 425 & 21 & 21,21 & 4,09 \\
\hline 2. & 100 & 100 & 75 & 200 & 475 & 18 & 18,18 & 4,5 \\
\hline 3. & 150 & 100 & 75 & 150 & 475 & 19 & 19,19 & 4,13 \\
\hline 4. & 150 & 100 & 100 & 150 & 500 & 7 & 7,07 & 4,35 \\
\hline 5. & 150 & 100 & 100 & 200 & 550 & 10 & 10,10 & 4,05 \\
\hline 6. & 150 & 100 & 75 & 200 & 525 & 14 & 14,14 & 4,17 \\
\hline 7. & 200 & 100 & 75 & 150 & 525 & 4 & 4,04 & 4,37 \\
\hline 8. & 200 & 100 & 75 & 200 & 575 & 6 & 6,06 & 4,08 \\
\hline Juml & 1200 & 800 & 625 & 1400 & 4050 & 99 & 100,00 & 33,74 \\
\hline Rata2 & 150 & 100 & 81,25 & 175 & 506,25 & & & \\
\hline
\end{tabular}

Sumber : Data Primer diolah 2012 
mencapai 40 \% ( Pramono dkk ., 2001) Kelebihan dan kekurangan pupuk akan berpengaruh terhadap pertumbuhan tanaman seperti kekurangan fosfat dapat mengakibatkan pertumbuhan tanaman menjadi kerdil, lamban pemasakan dan produksi tanaman rendah. (Hakim, dkk, 1986). Menurut Hakim dkk ( 1986), kalium mempunyai fungsi penting dalam proses fisiologi tanaman, yaitu dalam metabolisme dan absorpsi hara. Kemampuan tanah untuk menyediakan kalium dapat diketahui dari susunan mineral yang terdapat dalam tanah. Umumnya mineral leusit dan biotit merupakan sumber langsung dalam kalium bagi tanaman. Gejala tanaman yang kekurangan kalium adalah daun menjadi mengerut atau kering terutama pada daun tua, walaupun tidak merata. Tanaman yang mengalami kekurangan unsur ini akan terlihat bercak merah coklat serta daunnya akan mengering dan mati, buah tumbuhan tidak semprna, kecil dan serta tidak tahan simpan (Soepardi, 1983 dalam mipianto, 2006)

\section{KESIMPULAN}

Berdasarkan hasil penelitian dapat ditarik kesimpulan sebagai berikut:

1. Masyarakat di Daerah Aliran Sungai Padang Guci sangat tergantung pada lahan sawah. Hal ini ditunjukan dengan jumlah penduduk yang mayoritas bekerja sebagai petani.

2. Produksi padi sawah pada Daerah Aliran Sungai Padang Guci belum optimal, sebagaimana terlihat dari hasil rata-rata 4,21 ton/ha yang lebih rendah dari potensial yang berkisar antara 5 ton/ha $-6,59$ ton/ha.
3. Karakteristik biofisik yang mempengaruhi produksi padi adalah varietas, irigasi dan pemupukan.

4. Karakteristik sosial ekonomi yang mempengaruhi produksi padi adalah umur petani dan tenaga kerja.

\section{DAFTAR PUSTAKA}

Barmin. 2002. Budidaya Tanaman Pangan. Jakarta. CV. Ricardo.

Basaruddin, dkk. 1997. Budidaya Padi Sawah di Lahan Pasang Surut. Badan Penelitian dan Pengembangan Pertanian.

Hakim, dkk. 1986. Dasar-Dasar Ilmu Tanah. Penerbit Universitas Lampung. Bandar lampung. $488 \mathrm{hlm}$. Makarim, A.K., U.G. Kartasasmita. 2000. Teknologi Produksi Padi Sawah. Pusat Penelitian dan Pengembangan Tanaman Pangan. Bogor.

Mipianto, 2006. Pengaruh Pemberian Pupuk Kantang dan Pupuk daun (plant catalys) terhadap pertumbuhan tanaman alpokat. Skripsi. Universitas Lampung. Lampung

Joko P, dkk. 2005. Upaya Peningkatan Produktivitas Padi Sawah Melalui Pendekatan Pengelolaan Tanaman dan Sumberdaya Terpadu. Jurnal Agrosains 7(1): 1-6.

Maspary. 2011. http://www/Pertanian/2012/dosisdan-cara-pemupukan-padi.html 8 Januari 2012.

Promono, dkk. 2005. Upaya Peningkatan Produktivitas Padi Sawah Melalui

Pendekatan Pengelolaan Tanaman dan Sumberdaya Terpadu. Jurnal Agrosains 7(1):1-6. 
Soepardi, G. 1983. Sifat dan Ciri Tanah. Institut Pertanian Bogor. Bogor. $591 \mathrm{hlm}$.

Vandalisna, 2008. Konservas Lahan Padi Sawah (Oryza sativa, L) dengan system pengolahan tanaman terpadu (PTT) Didesa Aman damai
Kecamatan Kuala kabupaten Langkat. Universitas sumatera Utara. Yusmaini. 2010. Determinant yang mempengaruhi efisiensi teknis budidaya kentang merah (Red Pontiac) di dataran sedang Bengkulu. Tesis. Universitas Bengkulu. Bengkulu. 